\title{
CO-PYROLYSIS OF SEWAGE SLUDGE AND MANURE
}

Nadia Ruiz-Gómez (nadiarui@unizar.es)a, Violeta Quispe (vquispe@unizar.es)a , Javier Ábrego (abrego@unizar.es)a , María Atienza-Martínez (atienza@unizar.es)ª,*, María Benita Murillo (murillo@unizar.es) ${ }^{\mathrm{a}}$, Gloria Gea (glogea@unizar.es) ${ }^{\mathrm{a}}$

${ }^{a}$ Thermochemical Processes Group (GPT), Aragon Institute for Engineering Research (I3A), Universidad Zaragoza, Spain

*Corresponding author:

Phone: $+34876555483 \quad$ Fax: +34976762043

E-mail: atienza@unizar.es

\section{ABSTRACT}

The management and valorization of residual organic matter, such as sewage sludge

2 and manure, is gaining interest because of the increasing volume of these residues, their

3 localized generation and the related problems. The anaerobic digestion of mixtures of

4 sewage sludge and manure could be performed due to the similarities between both

5 residues. The purpose of this study is to evaluate the feasibility of the co-pyrolysis of

6 sewage sludge (SS) and digested manure (DM) as a potential management technology for

7 these residues. Pyrolysis of a sewage sludge/manure blend (50:50\%) was performed at

$8525{ }^{\circ} \mathrm{C}$ in a stirred batch reactor under $\mathrm{N}_{2}$ atmosphere. The product yields and some

9 characteristics of the product were analyzed and compared to the results obtained in the pyrolysis of pure residues. Potential synergetic and antagonist effects during the copyrolysis process were evaluated. Although sewage sludge and manure seem similar in nature, there are differences in their pyrolysis product properties and distribution due to their distinct ash and organic matter composition. For the co-pyrolysis of SS and DM, the 
product yields did not show noticeable synergistic effects with the exception of the yields of organic compounds, being slightly higher than the predicted average, and the $\mathrm{H}_{2}$ yield, being lower than expected. Co-pyrolysis of SS and DM could be a feasible management alternative for these residues in locations where both residues are generated, since the benefits and the drawbacks of the co-pyrolysis are similar to those of the pyrolysis of each residue.

KEYWORDS: sewage sludge; manure; co-pyrolysis; stirred batch reactor.

\section{INTRODUCTION}

The management and valorization of residual organic matter is a subject of growing interest because of the increasing volume of these residues, their localized generation and the associated environmental, economic and social issues. Sewage sludge and manure are two of the most abundant residues of this kind in Spain. The annual production of sewage sludge and livestock manure was 2.6 and $6 \mathrm{Mt}$ (on a dry basis), respectively, in recent years in Spain (Eurostat, 2014). The residues are similar in nature, in terms of high water and nutrient ( $\mathrm{N}$ and $\mathrm{P}$ ) content. For this reason, one of the traditional disposal methods for both residues is land application. However, this practice is limited by environmental regulations and transportation costs. The improper application of these residues to fields, especially in those regions with high concentrations of intensive livestock production, provokes surface and groundwater pollution, odor and air emissions (ammonia and greenhouse gases), and the accumulation of heavy metals in soils. In the specific region of Aragón in Spain, only its capital is densely populated (Zaragoza, around 700,000 inhabitants). Rural areas around it are scarcely populated but some of them have a flourishing farming sector. As a result, around $82 \mathrm{kt} /$ year of sewage sludge are generated, most of them in the area of Zaragoza. On the other hand, more than 11.5 and 2.3 Mt/year of pig and cattle manure are generated in Aragón. This quantity largely 
exceeds the local demand for agricultural fertilizers (in terms of $\mathrm{N}$ content). Thus, at least a portion of these residues could be co-processed together with sewage sludge. This possibility is encouraged by the Integrated Waste Management Plan of Aragón (GIRA), which aims to achieve a better valorization of the residue flows within the region, while enabling the optimum operation of existing and new treatment plants. Moreover, integrated approaches are demanded for the valorization of residual organic matter such as sewage sludge, manure and/or municipal solid wastes. Therefore, the development of alternative technologies for the management of these kinds of residues is required. In this regard, the pyrolysis of anaerobically digested organic-based wastes appears as a potential method for valorizing these residues. This process stabilizes them, reduces their volume, and produces three product fractions (solid, liquid and gas) valuable for energy and/or chemical production.

The EU Framework Programme for Research and Innovation establishes the need for seeking innovative and sustainable technologies for the management of manure and other effluents from livestock production. A similar approach is applied to sewage sludge. The pyrolysis of each one of these residues has been investigated in the past; for instance, the pyrolysis of sewage sludge has been widely studied for liquid production (Fonts et al., 2012) and also for obtaining solid products that can be used as adsorbents (Smith et al., 2009). Most of the works on liquid obtained from sewage sludge pyrolysis have been focused on its application as a fuel, but its high nitrogen content hinders this usage. For this reason, more recently the use of sewage sludge pyrolysis liquid as a source of valuable chemicals has been investigated (Fonts et al., 2016). Regarding manure pyrolysis, most research works have been devoted to producing biochar for its application as a soil conditioner, showing several benefits as an organic amendment (Meng et al., 2013; Subedi et al., 2016). Studies on manure pyrolysis to produce bio-oil have been 
sparse (Cao et al., 2011; Jeong et al., 2015) and mainly focused on poultry manure (Agblevor et al., 2010; Das et al., 2009), showing, as in the case of the bio-oil from sewage sludge, a relatively high nitrogen content compared to lignocellulosic biomass bio-oils.

Other authors have evaluated the co-pyrolysis of sewage sludge and lignocellulosic biomass in order to enhance the properties of the liquid for use as a fuel (Alvarez et al., 2015; Samanya et al., 2012) and to reduce the heat demand of the pyrolysis process (Ding and Jiang, 2013), proposing this co-pyrolysis as a viable solution for the valorization of sewage sludge (Alvarez et al., 2015) without external energy input (Ding and Jiang, 2013). The co-pyrolysis of manure with lignocellulosic biomass (Troy et al., 2013) and with agricultural plastic wastes (Ro et al., 2014) has also been evaluated with the aim of decreasing the energy requirements in the manure pyrolysis process without affecting the biochar properties.

Due to the similarities between sewage sludge and manure, the anaerobic digestion of their mixtures could be performed in locations where both residues are generated locally. Therefore, it would seem desirable to assess the co-pyrolysis of digested sewage sludge and manure with the aim of evaluating the feasibility of their joint valorization. However, the co-pyrolysis of both residues and its potential benefits has been scarcely studied (Sanchez et al., 2007). Sánchez et al. carried out a pilot-scale pyrolysis process for the treatment of a mixture of sewage sludge and cattle manure to evaluate the energetic valorization of the co-pyrolysis products, concluding that the co-pyrolysis products can be used as a fuel provided that the combustion gases are treated (Sanchez et al., 2007). In order to study the technical feasibility of co-pyrolizing these residues it would be necessary to assess the possible antagonist or the synergetic effects of the mixture of sewage sludge and manure on the pyrolysis product properties. However, these effects have barely been analyzed. Furthermore, it would be also interesting to assess the 
economic feasibility of this process (Brown et al., 2013; Wright et al., 2010).

90 The purpose of this study is to compare the main properties of the pyrolysis products

91 obtained from digested sewage sludge (SS) and digested manure (DM) and to ascertain

92 the potential synergetic and antagonist effects during the co-pyrolysis process.

\section{2. MATERIALS AND METHODS}

$94 \quad 2.1 \quad$ Materials.

95 The anaerobically digested and thermally dried SS used for this work was supplied by 96 an urban wastewater treatment plant located in Madrid (Spain). The DM was supplied by 97 the HTN Biogas Company located in Navarra (Spain) and was obtained by anaerobic co98 digestion of cattle manure with food and agro-industry wastes. The anaerobically digested 99 manure was separated in a decanter centrifuge and the solid fraction was dried at $105^{\circ} \mathrm{C}$.

100 The proximate and ultimate analysis, the higher heating value, the density and $\mathrm{pH}$ of these 101 materials contents are displayed in Table 1. The extractive content of both materials, also 102 shown in Table 1, was determined by Soxhlet extraction with dichloromethane. The 103 content of other organic macromolecules in SS and DM are also displayed in Table 1. 
Table 1. Properties of the materials (wet basis).

\begin{tabular}{|c|c|c|c|}
\hline Properties & Analytical standard & SS & $\mathrm{DM}$ \\
\hline $\begin{array}{l}\text { Ultimate analysis } \\
\text { (wt. \%) }\end{array}$ & & & \\
\hline Carbon $^{\mathrm{a}}$ & & 27.9 & 31.7 \\
\hline Hydrogen $^{\mathrm{a}, \mathrm{b}}$ & & 4.7 & 4.2 \\
\hline Nitrogen $^{\mathrm{a}}$ & & 4.5 & 1.9 \\
\hline Sulfur ${ }^{\mathrm{a}}$ & & 1.4 & 0.5 \\
\hline Oxygen $^{c}$ & & 34.6 & 50.7 \\
\hline $\begin{array}{l}\text { Proximate analysis } \\
\text { (wt. \%) }\end{array}$ & & & \\
\hline Dry matter & ISO-589-1981 & 93 & 87 \\
\hline Ash & ISO-18122-2015 & 40 & 20 \\
\hline Volatiles & ISO-5623-1974 & 50 & 54 \\
\hline Fixed carbon $^{\mathrm{d}}$ & & 3 & 13 \\
\hline \multicolumn{4}{|l|}{ Others } \\
\hline $\mathrm{HHV}^{\mathrm{e}}\left(\mathrm{MJ} \cdot \mathrm{kg}^{-1}\right)$ & ISO-1928-2009 & 12.5 & 13.9 \\
\hline Density $^{\mathrm{f}}\left(\mathrm{kg} \cdot \mathrm{m}^{-3}\right)$ & & 0.87 & 0.26 \\
\hline $\mathrm{pH}^{\mathrm{g}}$ & & 7.3 & 8.3 \\
\hline Extractives (wt. \%) & & 3.5 & 1.0 \\
\hline Protein (wt. \%) & EN-13342:2001 & 28 & 12 \\
\hline $\begin{array}{l}\text { Neutral detergent fiber } \\
\text { (NDF) (wt. \%) }\end{array}$ & XP U44-162 & 26.78 & 49.54 \\
\hline $\begin{array}{l}\text { Acid detergent fiber (ADF) } \\
\text { (wt. \%) }\end{array}$ & XP U44-162 & 4.26 & 46.77 \\
\hline Lignin (wt. \%) & XP U44-162 & 0.03 & 16.34 \\
\hline NDF-ADF ${ }^{\mathrm{h}}$ (wt. \%) & & 22.52 & 2.77 \\
\hline
\end{tabular}


a Ultimate analysis was performed using Carlo Erba 1108. ${ }^{\text {b}}$ The wt.\% of hydrogen includes 106 hydrogen from the moisture. ${ }^{\circ}$ Oxygen (\% wt) = 100-Carbon (\%)-Hydrogen (\%)-Nitrogen (\%)107 Sulfur (\%)-other elements contained in the ash (\%) (see Table 2). ${ }^{\mathrm{d} B y}$ difference. ${ }^{\mathrm{e}} \mathrm{HHV}$ was determined using IKA C 2000 Basic Calorimeter. ${ }^{\mathrm{f}} \mathrm{A}$ known volume of material $(25 \mathrm{~mL})$ was weighed and the density was calculated. ${ }^{\mathrm{g}} 1 \mathrm{~g}$ of solid is stirred for $1.5 \mathrm{~h}$ in demineralised water. ${ }^{\mathrm{h}}$ This fraction includes components such as hemicellulose. ${ }^{\text {TTh }}$ This fraction includes components such as cellulose.

Compared to lignocellulosic biomass wastes, SS and DM have higher ash, nitrogen and sulfur contents. The lower ash content of DM (half of that from SS) explains the higher higher heating value (HHV) of this type of residue. The higher oxygen content for $\mathrm{DM}$ is not only due to its higher moisture content, but also to its organic chemical composition. This higher oxygen content justifies the lower HHV (if expressed in dry ash free basis) of DM than that of SS (20 vs. $23 \mathrm{MJ} \cdot \mathrm{kg}^{-1}$ ). Another difference between both raw materials lies in their density, this being much lower for DM. Finally, the extractive and protein content was higher in SS than in DM. The extractives are the most non-polar compounds. The composition of the extractives was analyzed by Gas Chromatography and Mass Spectrometry (GC-MS). The compounds found in the extractives from SS were mainly fatty acids, toluene, benzene derivatives and steroids. The extractive compounds from DM were also fatty acids, toluene and phenolic compounds. DM contains larger amounts of lignin.

The high ash content in both materials could affect the pyrolysis process, since ash has been shown to have some catalytic effects (Aznar et al., 2007). The inorganic compounds found in the ash could increase the yield of char and non-condensable gases (NCG), and decrease the yield of liquid (Sekiguchi and Shafizadeh, 1984). According to Nik-Azar et al. (1997) Na and K have stronger catalytic effect than calcium. Table 2 displays the metal content of the wastes determined by Inductively Coupled Plasma-Atomic Emission 
133 As can be seen in Table 2, calcium and iron are the most abundant metals in DM and 134 SS ash, respectively.

135 Table 2. Metal content of SS and DM.

\begin{tabular}{|l|c|c|}
\hline Element & $\mathrm{SS}^{\left(\mathrm{g} \cdot \mathrm{kg}^{-1}\right)}$ & $\mathrm{DM}\left(\mathrm{g} \cdot \mathrm{kg}^{-1}\right)$ \\
\hline $\mathrm{Al}$ & 21.75 & 9.04 \\
$\mathrm{As}$ & $<0.035$ & $<0.035$ \\
$\mathrm{Ba}$ & 0.333 & 0.024 \\
$\mathrm{Ca}$ & 22.99 & 55.4 \\
$\mathrm{Cd}$ & $<0.004$ & $<0.004$ \\
$\mathrm{Co}$ & $<0.007$ & $<0.007$ \\
$\mathrm{Cr}$ & 0.080 & $<0.065$ \\
$\mathrm{Cu}$ & 0.41 & $<0.034$ \\
$\mathrm{Fe}$ & 66.80 & 7.86 \\
$\mathrm{~K}$ & 5.03 & 8.64 \\
$\mathrm{Mg}$ & 6.81 & 8.09 \\
$\mathrm{Mn}$ & 0.25 & 0.30 \\
$\mathrm{Mo}$ & $<0.165$ & $<0.165$ \\
$\mathrm{Ni}$ & $<0.021$ & $<0.021$ \\
$\mathrm{P}$ & 30.81 & 15.16 \\
$\mathrm{~Pb}$ & 0.183 & $<0.133$ \\
$\mathrm{Ti}$ & 1.5 & $<0.023$ \\
$\mathrm{Zn}$ & $<0.026$ & 0.33 \\
$\mathrm{Hg}$ & $<0.026$ & $<0.026$ \\
$\mathrm{Na}$ & 2.33 & 4.83 \\
$\mathrm{Si}$ & 48.8 & 0.39 \\
\hline
\end{tabular}

137 Figure 1 shows the Fourier transform infrared (FTIR) spectra of both residues. 


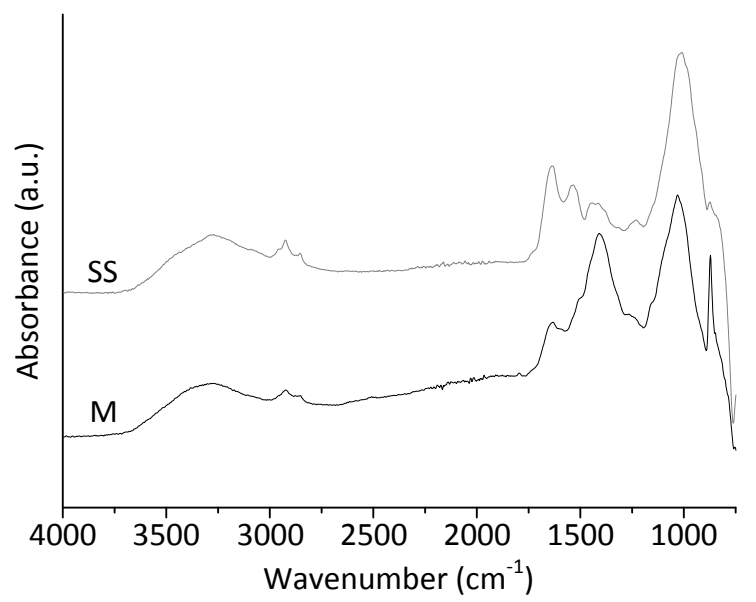

Figure 1. FTIR spectra of SS and DM.

In general, the SS used shows a similar spectrum to others previously reported (Abrego

et al., 2009), the main differences (e.g. lower peak intensities) being attributable to the effect of the anaerobic digestion, which greatly reduces the intensity of some bands (Cuetos et al., 2013). The DM used in this work was also anaerobically digested and thus also exhibits broad bands with lower intensities. The comparison between both materials shows some similarities and several differences. Both of them show a band in the 1200-

$1471000 \mathrm{~cm}^{-1}$ range attributed to polysaccharides. However, DM shows a distinctive band centered at $1409 \mathrm{~cm}^{-1}$ that could be explained by $\mathrm{C}=\mathrm{O}$ stretching and $\mathrm{OH}$ deformation from carboxylic acids (Socrates, 2004). The presence of a higher number of these 150 functional groups in DM could partly explain the higher O content of this material. On 151 the other hand, the bands related to compounds with a protein origin (1790-1500 $\mathrm{cm}^{-1}$ ) 152 (Cuetos et al., 2013) are much more intense in the case of SS, which is in accordance with the higher $\mathrm{N}$ content of this material. The peak at $2800-3000 \mathrm{~cm}^{-1}$ indicates the presence 154 of aromatic and aliphatic structures. The broad band between $3000-3700 \mathrm{~cm}^{-1}$ 155 corresponds to the $\mathrm{O}-\mathrm{H}$ stretching in water, alcohols, phenols and carboxylic acids, as well as N-H stretching from amides and amines (Alvarez et al., 2015). Finally, the very 
157 high calcium content in DM could be evidenced by the sharp peak appearing in its spectrum at around $875 \mathrm{~cm}^{-1}$, corresponding to calcium carbonate (Abrego et al., 2009). Another characteristic band for this compound appears at around $1420 \mathrm{~cm}^{-1}$ and could contribute to the previously mentioned band found at $1409 \mathrm{~cm}^{-1}$.

3.

Table 3. Particle size distribution for the raw materials.

\begin{tabular}{|l|c|c|}
\hline Size $(\mathrm{mm})$ & DM (wt. \%) & SS (wt. \%) \\
\hline$\Phi>4$ & 23 & 2 \\
$3<\Phi<4$ & 9 & 54 \\
$2<\Phi<3$ & 17 & 40 \\
$0.8<\Phi 2$ & 30 & 2 \\
$\Phi<0.8$ & 21 & 2 \\
\hline
\end{tabular}

2.2. Experimental system and procedure

Thermogravimetric analyses were performed prior to the pyrolysis runs in the stirred batch reactor. Both experimental systems are briefly described below.

\subsubsection{Thermogravimetric analysis (TGA)}

Thermogravimetric analyses were performed in order to study the thermal degradation

171 behavior of each residue and of the 50:50\% blend. A Netzsch STA 449 Jupiter ${ }^{\circledR}$

172 thermobalance was used. The two materials were ground and sieved to a particle size lower than $50 \mu \mathrm{m}$. The SS/DM blend (50\%:50\%) was prepared by blending both wastes, ground and sieved. The operating conditions used were the same for the three samples (SS, DM and SS/DM). The samples (ca. $20 \mathrm{mg}$ ) were heated up to $900{ }^{\circ} \mathrm{C}$ at a heating rate 176 of $10^{\circ} \mathrm{C} \cdot \mathrm{min}^{-1}$ under $\mathrm{N}_{2}$ atmosphere (flow rate of $50 \mathrm{~mL}(\mathrm{STP}) \cdot \mathrm{min}^{-1}$ ). Two replicates 
were performed for each feedstock.

178

179

180

181

182

183

184

185

186

187

188

189

190

191

192

193

194

2.2.2. Pyrolysis tests in the stirred batch reactor.

A bench-scale stirred batch reactor was used to pyrolyze each residue alone (SS and $\mathrm{DM}$ ) and also the 50:50\% blend (SS/DM). Figure 2 illustrates the laboratory scale setup. The cylindrical reactor has a diameter of $107 \mathrm{~mm}$ and a length of $294 \mathrm{~mm}$. The reactor capacity depends on the bulk density of the solid material fed. Since the bulk density of SS is higher, the amount of sample placed in the reactor was approximately $600 \mathrm{~g}$ for SS pyrolysis runs and around $300 \mathrm{~g}$ for DM and SS/DM runs. Four K-type thermocouples were used to register the temperature profiles in the reactor. The pyrolysis experiments were performed under $\mathrm{N}_{2}$ atmosphere $\left(250 \mathrm{~mL}(\mathrm{STP}) \cdot \mathrm{min}^{-1}\right.$ ) at $525^{\circ} \mathrm{C}$ as the final temperature and at a heating rate of around $8{ }^{\circ} \mathrm{C} \cdot \mathrm{min}^{-1}$ (this was the maximum heating rate achievable by the experimental system). The final temperature was maintained for $30 \mathrm{~min}$. The vapors produced during the pyrolysis process passed through the condensing zone. The condensable fraction (water and organic compounds) was collected in two icecooled condensers and one electrostatic precipitator. The composition of NCG was analyzed by a micro-gas chromatograph (micro-GC) connected online. Specifically, the analyzed gases were $\mathrm{CO}_{2}, \mathrm{CO}, \mathrm{H}_{2}, \mathrm{CH}_{4}, \mathrm{C}_{2} \mathrm{H}_{2}, \mathrm{C}_{2} \mathrm{H}_{4}, \mathrm{C}_{2} \mathrm{H}_{6}$ and $\mathrm{H}_{2} \mathrm{~S}$. The experiments were conducted in duplicate. 


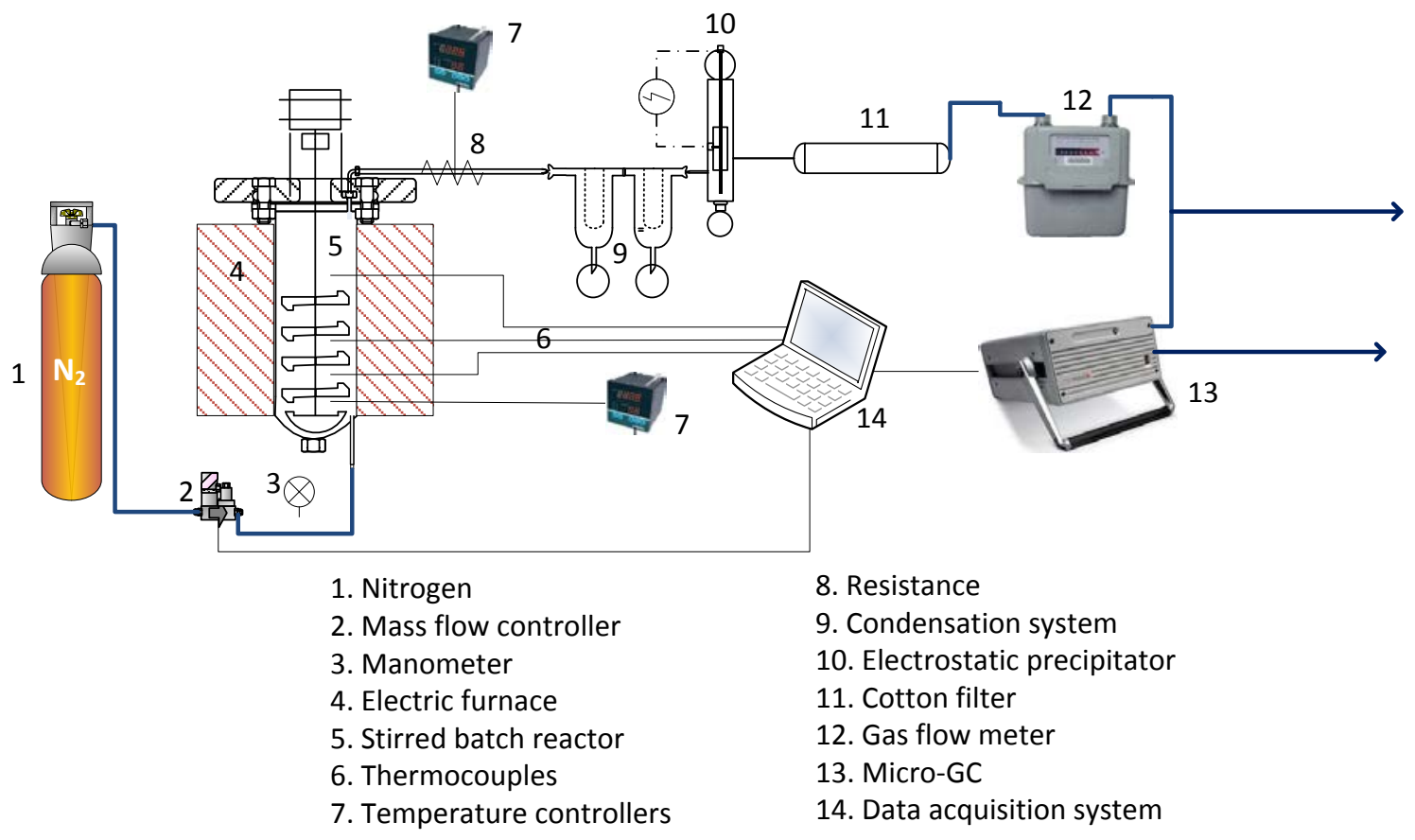

Figure 2. Laboratory scale pyrolysis setup.

2.2.3 Characterization of pyrolysis products

The mass yields of each one of the pyrolysis products ( $\eta_{\text {product }}$ ) were calculated as the percentage ratio between the mass of pyrolysis product and the mass of feedstock introduced into the reactor. The mass of solid (char) and liquid obtained was determined gravimetrically. The mass of gas obtained was calculated taking into account the gas composition provided by the micro-GC and the known volumetric flow of nitrogen introduced. the gas composition and the lower heating value of each gas compound. The ultimate and proximate analyses and the higher heating value of the char $\left(\mathrm{HHV}_{\text {char }}\right)$ obtained in each experiment were determined. The FTIR analysis of the char was also performed and the results were compared to the FTIR spectra of the different residues. 
The liquid, which separated into two phases (aqueous phase (AP) and organic phase

211 (OP)) in all the experiments performed, was centrifuged at $4500 \mathrm{rpm}$ (2038 $\mathrm{xg}$ ) for 30 min using a Heraeus Megafuge 16 Centrifuge to separate both phases. The phases were stored in a fridge at between $3{ }^{\circ} \mathrm{C}$ and $5{ }^{\circ} \mathrm{C}$ until they were analyzed. The water content

214 (WC, mass fraction \%) of each phase was determined by the Karl-Fischer titration method. The density of both phases was determined using a portable Mettler Toledo densimeter (model Densito 30 PX). The ultimate analysis and the higher heating value of the organic phase $\left(\mathrm{HHV}_{\mathrm{OP}}\right)$ were also measured. The organic compounds present in both phases were identified and semi-quantified by GC-MS and GC-FID. The chromatographic methods used for both phases showed certain differences. The capillary column used for analyzing the aqueous phases was a $50 \mathrm{~m}$ x $200 \mu \mathrm{m}$ x $0.3 \mu \mathrm{m}$ HP-FFAP Polyethylene Glycol TP. Helium of $99.999 \%$ purity was used as the carrier gas and the injector temperature was set at $300^{\circ} \mathrm{C}$. The temperature program adopted was the following: initial oven temperature at $60{ }^{\circ} \mathrm{C}$ held for 6 min followed by an increase to $80^{\circ} \mathrm{C}$ at a rate of $1.5^{\circ} \mathrm{C} \cdot \mathrm{min}^{-1}$ and held for $5 \mathrm{~min}$, consequently increased to $200{ }^{\circ} \mathrm{C}$ at a rate of $1{ }^{\circ} \mathrm{C} \cdot \mathrm{min}^{-1}$ and held for $5 \mathrm{~min}$, and finally increased to $240{ }^{\circ} \mathrm{C}$ at a rate of $1.8^{\circ} \mathrm{C}$ $\min ^{-1}$ where it was held for $30 \mathrm{~min}$. The capillary column used for the organic phases was $60 \mathrm{~m} \times 250 \mu \mathrm{m} \times 0.25 \mu \mathrm{m}$ DB-17ms. The carrier gas and the injector temperature were similar to those used for the aqueous phases. The temperature program was as follows: initial oven temperature at $60^{\circ} \mathrm{C}$ held for $5 \mathrm{~min}$ followed by an increase to $250{ }^{\circ} \mathrm{C}$ at a rate of $1.5^{\circ} \mathrm{C} \mathrm{min}{ }^{-1}$ and held for $5 \mathrm{~min}$, and finally an increase to $310^{\circ} \mathrm{C}$ at a rate of $2{ }^{\circ} \mathrm{C} \cdot \mathrm{min}^{-}$ ${ }^{1}$ and held for $5 \mathrm{~min}$. The analysis procedure used considers all the response factors to be similar. It therefore does not give quantitative results but is suitable for comparing relative percentages of compounds in pyrolysis liquids. 
calculated for each run.

236 energy yield $_{i}=\frac{\eta_{i} H H V_{i}}{H H V} \times 100$

237 where $\eta_{\mathrm{i}}$ and $\mathrm{HHV}_{\mathrm{i}}$ are the mass yield and the higher heating value of each pyrolysis product (gas, organic liquid phase and char, respectively) and HHV is the higher heating

239 value of the material introduced into the reactor (or the average of HHVs in the case of 240 SS/DM).

241 Finally, the energy requirement for the pyrolysis process was estimated for each waste 242 and the blend. The procedure followed to solve the energy balances was similar to those 243 used by other researchers (Abrego et al., 2013; Atienza-Martinez et al., 2015; Gil244 Lalaguna et al., 2014).

\section{RESULTS AND DISCUSSION}

\subsection{TGA experiments}

The mass loss (TG) and derivative mass loss (DTG) curves are displayed in Figure 3.

Both materials show total mass loss greater than $50 \%$ at the final temperature of $900{ }^{\circ} \mathrm{C}$ and a main decomposition stage in the temperature interval between 200 and $400{ }^{\circ} \mathrm{C}$. This stage begins slightly later for DM than for SS (DTG peaks at $325^{\circ} \mathrm{C}$ and $310{ }^{\circ} \mathrm{C}$, respectively) which could be explained by the higher cellulose content in DM. Immediately after this main decomposition stage, SS shows additional mass loss

254 evidenced by a shoulder in its DTG curve, which can be associated with protein decomposition. The region between 500 and $650{ }^{\circ} \mathrm{C}$ is quite similar for both materials, with relatively constant mass loss. Major differences arise at higher temperatures, with more significant mass loss for DM peaking at $715^{\circ} \mathrm{C}$. This peak may be attributed to 
calcium carbonate decomposition (Abrego et al., 2009). This compound has been identified in the FTIR spectrum of DM (Figure 1). Furthermore, calcium is the most abundant component of the $\mathrm{DM}$ ashes, and the manure $\mathrm{pH}$, higher than 7 , indicates a significant proportion of carbonates in the ashes (Schumacher, 2002).

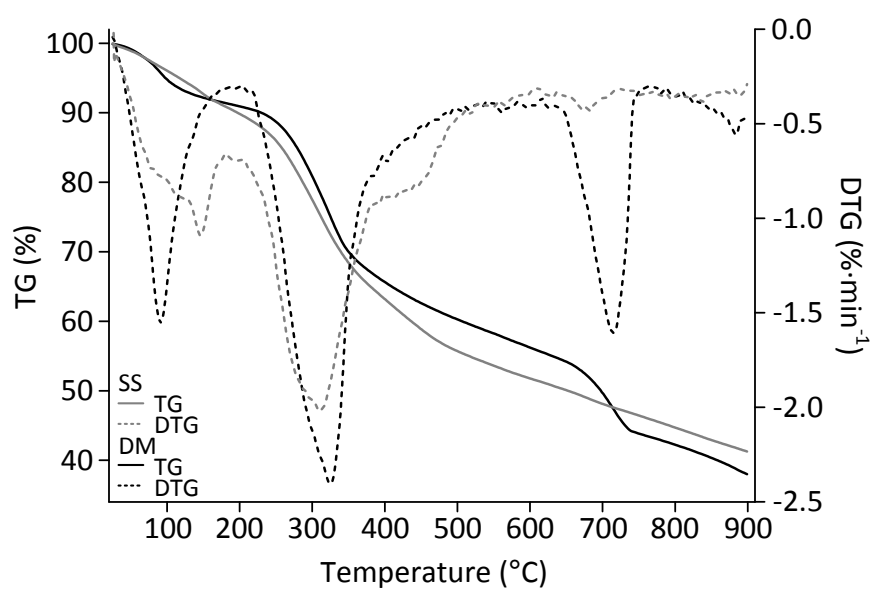

Figure 3. Mass loss (TG) and derivative mass loss (DTG) curves for SS and DM.

The experimental and the predicted (arithmetic average from the results obtained for each material) DTG curves for SS/DM are compared in Figure 4 in order to assess potential synergistic effects. In order to better compare the main decomposition features, the drying region, below $100{ }^{\circ} \mathrm{C}$, is not shown in the figure. The predicted and the experimental curves were quite similar. The region below $500{ }^{\circ} \mathrm{C}$ was almost identical, with a minor difference in the DTG peak maximum (the predicted curve showed a DTG peak maximum at $318.5^{\circ} \mathrm{C}$, whereas the experimental curve gave $312.5^{\circ} \mathrm{C}$ ). At higher temperatures, experimental data showed lower mass loss than predicted, especially from $700{ }^{\circ} \mathrm{C}$. It seems that the carbonate decomposition region already shown for DM in Figure 3 was affected in two ways by the presence of SS. On the one hand, the experimental DTG temperature peak was $698.5^{\circ} \mathrm{C}$ vs. the predicted peak at $713.5^{\circ} \mathrm{C}$. On the other hand, the total mass loss in this stage was lower than the arithmetic average of both 


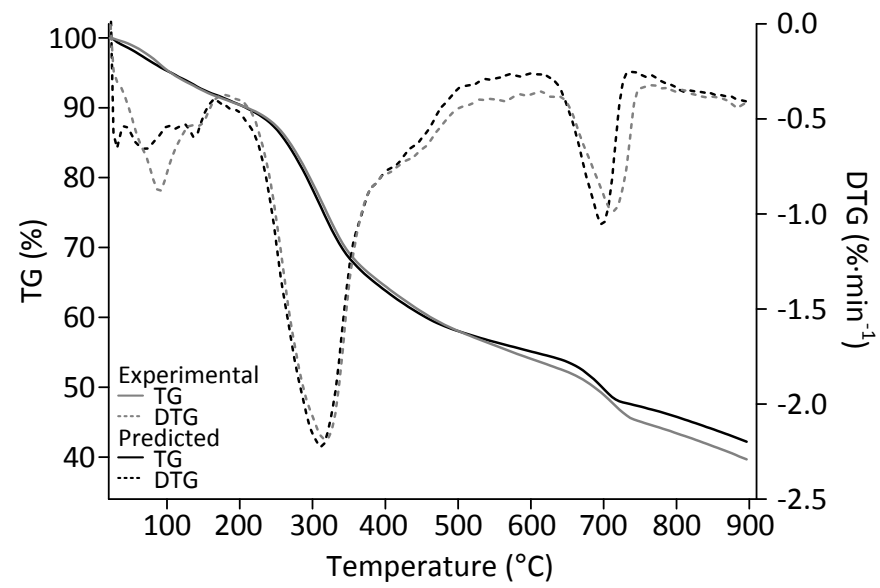

Figure 4. Experimental and predicted TG and DTG curves for SS/DM blend. Pyrolysis product yields from the pyrolysis of each residue and from the co-pyrolysis of both are displayed in Figure 5. The predicted average yields are also shown in Figure 5.

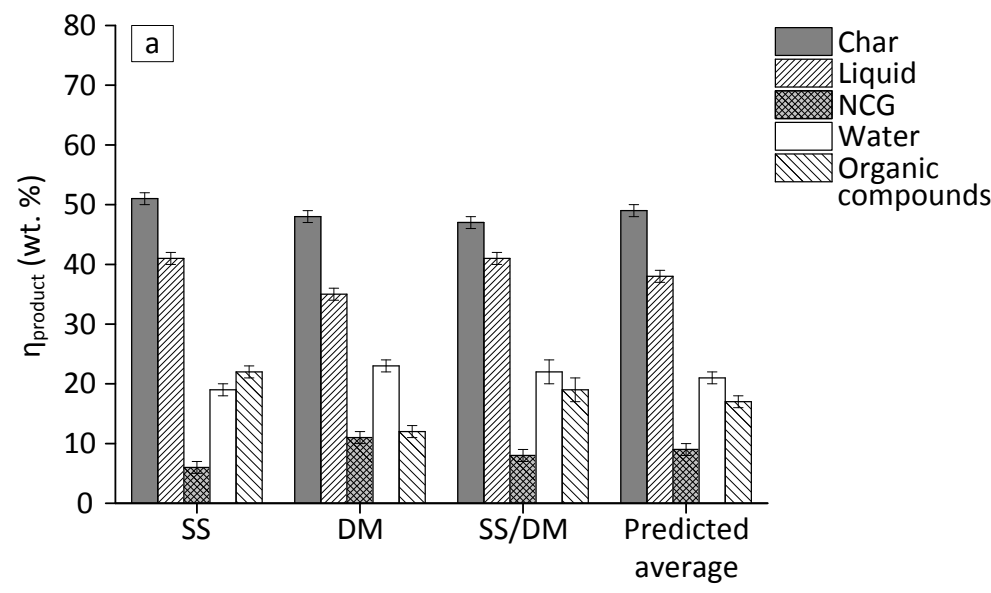




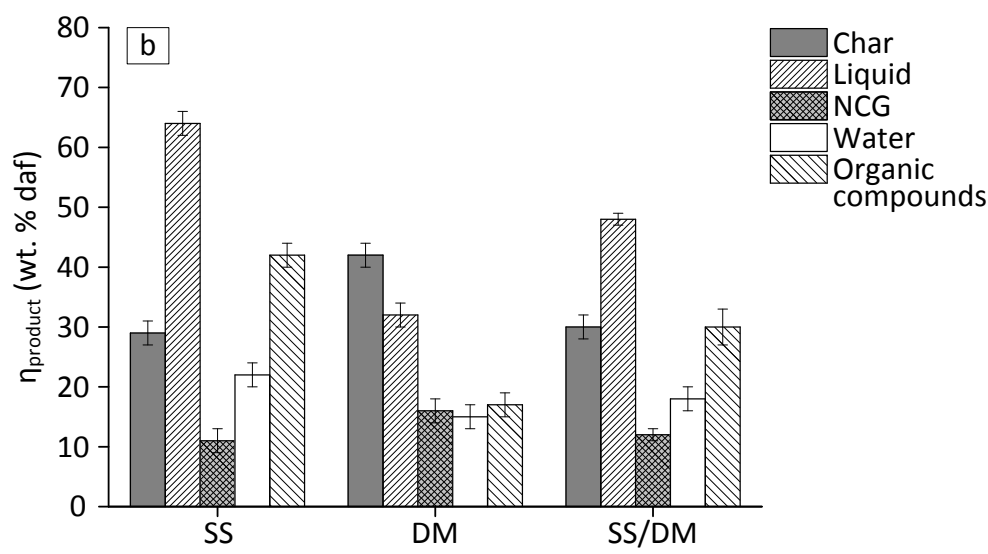

Figure 5. a) Product yields, expressed on feedstock basis, from the pyrolysis of SS,

$\mathrm{DM}$ and SS/DM b) Product yields, expressed on a dry ash free basis, from the pyrolysis of SS, DM and SS/DM.

Although sewage sludge and manure are not very different in nature, their pyrolysis product distribution showed certain differences. The pyrolysis of DM produced a higher gas yield, and lower char and liquid yields than the pyrolysis of SS (Figure 5a). The higher ash content of SS explains its higher char yield. However, if expressed on a dry ash free basis, the char yield from the DM pyrolysis is higher than that from SS (see Figure 5b). These results are in accordance with the higher fixed carbon content of the DM (see Table 1), which could be justified by its higher lignin content and lower extractives content. It is known that the char yield from the pyrolysis of lignin is high (Qu et al., 2011) whereas the char yield from the pyrolysis of lipids or extractives is low. Sewage sludge contains a higher proportion of proteins and the char from the pyrolysis of proteins is also high (Kebelmann et al., 2013), but not as high as that from lignin. The higher gas yield from the pyrolysis of DM could be attributed to the catalytic activity of the metals present in the ash (Manya et al., 2006). DM contains higher concentrations of Ca and Na than SS 
species would promote the degradation of the organic matter, favoring the gas formation (Zabeti et al., 2012). The higher moisture content of DM could explain the higher water yield from the pyrolysis of DM. However, the water yield expressed on dry ash free basis was lower using DM as the feedstock (see Figure $5 b$ ). The water generated by the pyrolysis reactions was higher in the case of the SS pyrolysis. The higher $\mathrm{H} / \mathrm{O}$ molar ratio in $\mathrm{SS}(\mathrm{H} / \mathrm{O}=2.2$ for SS vs. $\mathrm{H} / \mathrm{O}=1.1$ for $\mathrm{DM}$, expressed on dry basis) makes it possible that a greater amount of the organic oxygen present in the starting material may be converted into water during the pyrolysis process (Mullen and Boateng, 2011). Other authors have observed that the pyrolysis of biomass with high protein content results in higher water production because of the reaction of nucleophilic amine groups with electrophilic oxygen groups releasing water (Mullen and Boateng, 2011). The DM used in this study has lower protein content than the SS, which could produce lower amounts of pyrolytic water and consequently a lower water yield, expressed on dry ash free basis. The amount of condensable organic compounds generated by pyrolysis was much lower for DM. DM has a lower amount of extractives than SS. Lipids generate a high level of volatiles (Kebelmann et al., 2013) which could explain the higher organic compound yield from SS. Furthermore, the presence of a higher content of some alkali metals such as $\mathrm{Ca}$ and $\mathrm{Na}$ in DM could also provoke a reduction in the yield of organic compounds, promoting the gas yield (Zabeti et al., 2012).

For the co-pyrolysis of SS and DM, the product yields showed an expected behavior, i.e. there were no noticeable synergistic effects, with the exception of the yield of organic compounds. The product yields obtained from the pyrolysis of the blend of SS and DM was approximately the average of the yields obtained from each individual residue (Figure 5a). However, the yield of organic compounds obtained from the pyrolysis of the SS/DM blend was slightly higher than the predicted average. This might be attributed to 
the reduction in the alkali metal content in the SS/DM blend feedstock compared to DM, causing the secondary reactions to occur to a lesser extent. Other authors have observed important synergies in the co-pyrolysis of sewage sludge and different types of lignocellulosic biomass, such as poplar sawdust (Zuo et al., 2014), rice husk (Zhang et al., 2015) and sawdust(Alvarez et al., 2015), which they have attributed to the catalytic activity of the ash present in the sewage sludge. The synergy resulted in increasing gas yields and decreasing bio-oil yields. The more similar ash content in SS and DM in comparison with lignocellulosic biomass could explain the lesser synergistic effect on the product yields between the two materials studied in this work.

\subsection{Gas characterization}

The yields of NCG obtained from the pyrolysis of each residue and the co-pyrolysis are displayed in Figures 6a and 6b. The major gas compound in all the experiments was $\mathrm{CO}_{2}$. The pyrolysis of SS produced lower yields of $\mathrm{CO}_{2}$ and $\mathrm{CO}$ and higher yields of $\mathrm{H}_{2}$ and $\mathrm{H}_{2} \mathrm{~S}$ than the DM pyrolysis. $\mathrm{CO}_{2}$ and $\mathrm{CO}$ derived from decarboxylation and decarbonylation reactions, respectively. The higher proportion of carbonyl and carboxyl groups in DM enhanced the formation of both $\mathrm{CO}_{2}$ and CO. Furthermore, $\mathrm{Na}$ and $\mathrm{Ca}$, which are present in higher proportions in DM, are active catalysts for generating $\mathrm{CO}_{2}$ and CO during pyrolysis (Zabeti et al., 2012). The higher molar ratio H/C in SS (1.6 for SS vs. 0.9 for DM, expressed on dry basis), together with the higher content of $\mathrm{Al}_{2} \mathrm{O}_{3}$ in the SS ashes which might promote $\mathrm{H}_{2}$ production (Azuara et al., 2013), could explain the higher $\mathrm{H}_{2}$ yield in the SS pyrolysis. Furthermore, the higher lignin content in DM disfavors $\mathrm{H}_{2}$ production, since lignin devolatilization generates less $\mathrm{H}_{2}$ than other chemical constituents, such as cellulose or hemicellulose ( $\mathrm{Li}$ et al., 2004). The lower $\mathrm{H}_{2} \mathrm{~S}$ yield from the pyrolysis of DM could be explained by the lower S content in this material. 
356 from the co-pyrolysis was lower than that calculated as the predicted average. This 357 antagonist effect might be attributed to the reduction in the Al content in the SS/DM blend 358 feedstock compared to SS.

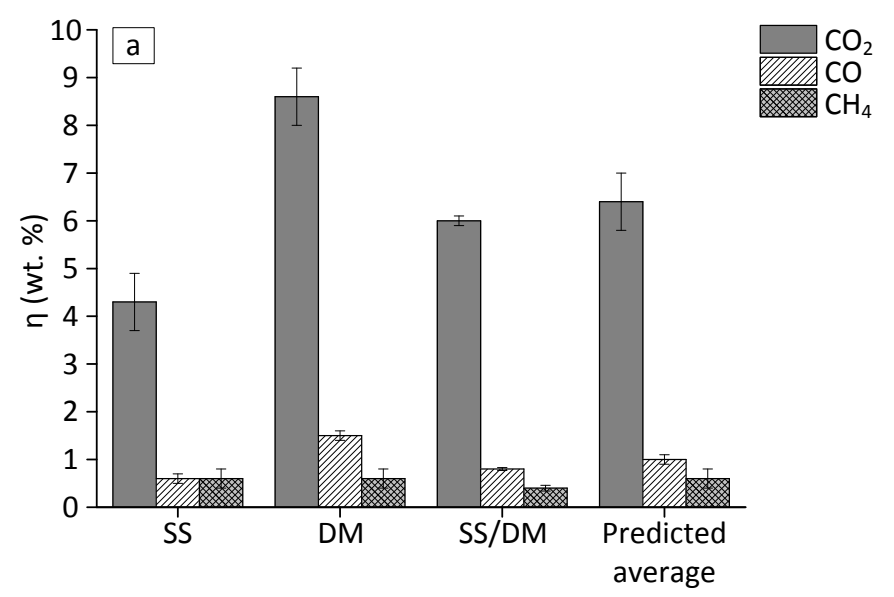

359

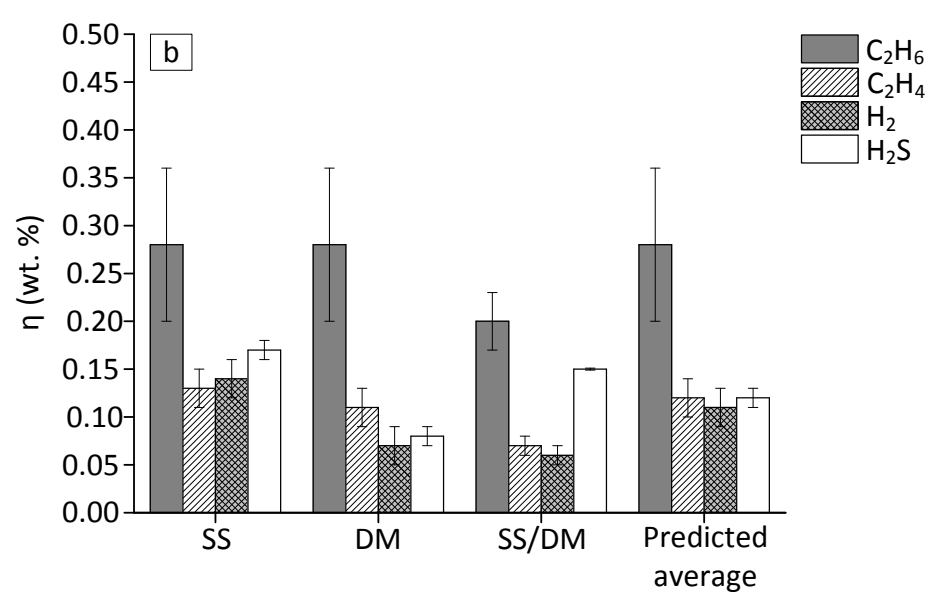

Figure 6. NCG yields from the pyrolysis of SS, DM and SS/DM blend a) $\mathrm{CO}_{2}$, CO, and $\mathrm{CH}_{4}$ yields, b) $\mathrm{H}_{2}, \mathrm{H}_{2} \mathrm{~S}, \mathrm{C}_{2} \mathrm{H}_{4}$, and $\mathrm{C}_{2} \mathrm{H}_{6}$ yields.

According to the gas composition, the $\mathrm{LHV}_{\text {gas }}\left(\mathrm{N}_{2}\right.$ free) from the DM pyrolysis (6 $\left.\pm 1 \mathrm{MJ} \cdot \mathrm{m}^{-3} \mathrm{STP}\right)$ was lower than that from the SS pyrolysis $\left(10 \pm 1 \mathrm{MJ} \cdot \mathrm{m}^{-3} \mathrm{STP}\right)$. The $\mathrm{LHV}_{\text {gas }}$ from the SS/DM co-pyrolysis $\left(6 \pm 1 \mathrm{MJ} \cdot \mathrm{m}^{-3} \mathrm{STP}\right)$ was similar to the $\mathrm{LHV}_{\text {gas }}$ from DM and lower than predicted average value $\left(8 \pm 1 \mathrm{MJ} \cdot \mathrm{m}^{-3} \mathrm{STP}\right)$ since, as already indicated, 368 the $\mathrm{H}_{2}$ yield is also lower. In any case, the LHV of the NCG produced from the three 
types of feedstock could be enough to use the gas as a fuel, although a system for cleaning combustion gases would be required.

\subsection{Liquid characterization}

The liquid product obtained from the pyrolysis of each residue is heterogeneous, showing two different phases (AP and OP, as stated in the Experimental Section). The AP was the major liquid phase in all the runs (Table 4). The OP yield was much lower from the DM than from the SS pyrolysis. However, the AP yield was similar for all the runs (Table 4). The OP yield obtained from the co-pyrolysis seemed to increase slightly more than the amount explainable by a predicted average, as was the case with the yield of organic compounds. Water was the major component present in the liquid. Table 4 shows the water content of the liquid phases obtained. The OP from the DM pyrolysis and from the co-pyrolysis showed a higher water proportion than the OP obtained from the SS pyrolysis. More polar organic compounds can be expected in the OP from the DM pyrolysis.

Table 4. Liquid phase yields (expressed on a feedstock basis) and water content. The values are expressed as mean \pm standard deviation

\begin{tabular}{|l|c|c|c|c|}
\hline Feedstock & \multicolumn{2}{|c|}{ Liquid phase yields (wt. \%) } & \multicolumn{2}{c|}{ Water content (wt. \%) } \\
\hline & OP & AP & OP & AP \\
\hline SS & $13 \pm 1$ & $28 \pm 1$ & $7 \pm 2$ & $63 \pm 1$ \\
DM & $5.5 \pm 0.5$ & $29.8 \pm 0.5$ & $17 \pm 6$ & $75 \pm 1$ \\
SS/DM & $11 \pm 1$ & $29 \pm 1$ & $15 \pm 5$ & $68 \pm 2$ \\
Predicted average & $9 \pm 1$ & $29 \pm 1$ & $12 \pm 6$ & $69 \pm 1$ \\
\hline
\end{tabular}

reflected the potential of these fractions for their use as liquid fuels. However, their nitrogen and sulfur contents, which are relatively high, hinder this application, since their combustion may lead to NOx and SOx generation. The N content in the organic phase 
390 from the pyrolysis of DM was lower than that of the OP from the pyrolysis of SS because

391 the N content in SS is higher. Nevertheless, the application of these OPs as a source of 392 valuable chemical products, such as N-containing compounds (amides, imidazoles and 393 pyridines, among others), could represent an opportunity for SS and DM, since there are 394 not too many renewable sources for these types of compound (Fonts et al., 2016). No 395 noticeable synergistic effects were reflected for the SS/DM blend in either the ultimate 396 analysis or the $\mathrm{H} / \mathrm{C}$ and $\mathrm{O} / \mathrm{C}$ molar ratios. 
397 Table 5. Ultimate analysis (dry basis), molar ratios $\mathrm{H} / \mathrm{C}$ and $\mathrm{O} / \mathrm{C}$ (dry basis), and higher 398 heating value of the organic phases (wet basis). The values are expressed as mean \pm 399 standard deviation

\begin{tabular}{|l|c|c|c|c|}
\hline & SS & DM & SS/DM & Predicted average \\
\hline Carbon (wt. \%) & $69 \pm 1$ & $69 \pm 5$ & $65 \pm 8$ & $69 \pm 5$ \\
Hydrogen (wt. \%) & $9 \pm 0.2$ & $7.2 \pm 0.4$ & $7 \pm 2$ & $8.0 \pm 0.4$ \\
Nitrogen (wt. \%) & $8.3 \pm 0.2$ & $4.9 \pm 0.2$ & $6.9 \pm 0.4$ & $6.6 \pm 0.2$ \\
Sulfur (wt. \%) & $1.9 \pm 0.2$ & $1.4 \pm 0.3$ & $1.9 \pm 0.5$ & $1.7 \pm 0.3$ \\
Oxygen (wt. \%) & $12 \pm 1$ & $18 \pm 5$ & $19 \pm 8$ & $15 \pm 5$ \\
H/C & 1.6 & 1.3 & 1.3 & 1.4 \\
O/C & 0.1 & 0.2 & 0.2 & 0.2 \\
HHV (MJ kg ${ }^{-1}$ ) & $34 \pm 2$ & $29 \pm 2$ & $29 \pm 4$ & $32 \pm 2$ \\
\hline
\end{tabular}

401

402 Table 6 shows the ultimate analyses of the aqueous phases and the $\mathrm{pH}$ of these phases.

403 As can be observed, the $\mathrm{pH}$ of the AP from the DM pyrolysis was lower than that of the 404 SS pyrolysis. 
Table 6. Ultimate analysis (dry basis) and $\mathrm{pH}$ for the aqueous phases. The values are

expressed as mean \pm standard deviation

\begin{tabular}{|l|c|c|c|c|}
\hline & SS & DM & SS/DM & Predicted average \\
\hline Carbon (wt. \%) & $27 \pm 1$ & $23 \pm 1$ & $24 \pm 1$ & $25 \pm 1$ \\
Hydrogen (wt. \%) & $7.2 \pm 0.3$ & $7.6 \pm 0.2$ & $6.6 \pm 0.4$ & $7.4 \pm 0.2$ \\
Nitrogen (wt. \%) & $16 \pm 1$ & $6 \pm 1$ & $11 \pm 2$ & $11 \pm 1$ \\
Sulfur (wt. \%) & $1.2 \pm 0.1$ & $0.43 \pm 0.05$ & $0.69 \pm 0.03$ & $0.8 \pm 0.1$ \\
pH & $9.5 \pm 0.5$ & $6 \pm 1$ & $8.7 \pm 0.2$ & $8 \pm 1$ \\
\hline
\end{tabular}

407

chemical families. The area percentage of each family identified is shown in Figure 7.

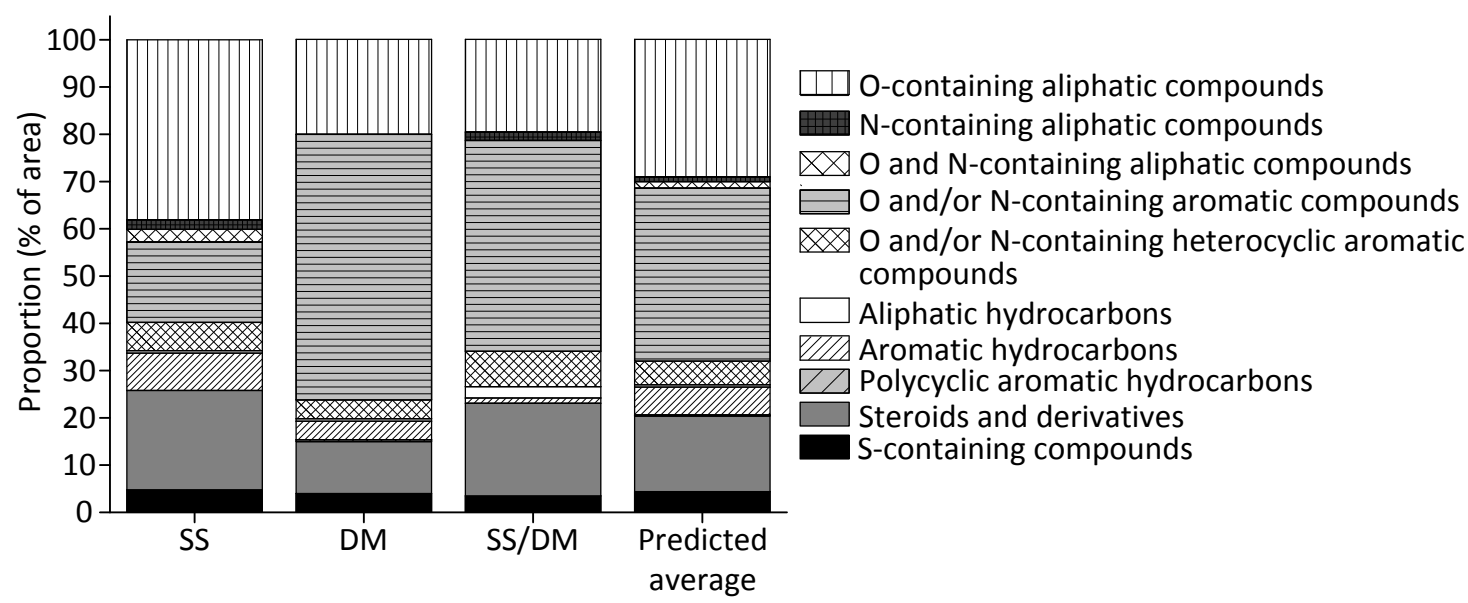

412 Figure 7. Composition of the OP obtained from the pyrolysis of SS, DM and SS/DM.

Table 7 shows the chromatographic area percentages of certain organic compounds

415 identified in the organic phase obtained in the co-pyrolysis of SS and DM, and of those derived from the pyrolysis of each material independently. 
417 Table 7. Chromatographic area percentage of certain organic compounds identified in the

418 OP obtained from the pyrolysis of SS, DM and SS/DM blend.

\begin{tabular}{|l|c|c|c|}
\hline & SS (\%) & DM (\%) & SS/DM (\%) \\
\hline Carboxylic acids & 31.8 & 13.0 & 10.7 \\
Alcohols & 1.3 & 3.2 & 2.5 \\
Nitriles & 3.2 & 0.0 & 2.9 \\
Phenols & 10.0 & 31.9 & 31.1 \\
Cholestenes & 12.2 & 1.3 & 8.4 \\
\hline
\end{tabular}

419

Oxygen-containing aliphatic compounds (mainly carboxylic acids), as well as steroids and their derivatives, were the main compounds in the OP from the pyrolysis of SS. However, the main organic compounds from the pyrolysis of DM were nitrogen and/or oxygen-containing aromatic compounds (mainly phenols). Fatty acids stem from their direct devolatilization from SS and DM, since the extractives of both residues also contain these compounds. The lower extractives content in DM could explain the lower proportion of steroids in the organic phase from DM. The OP from the pyrolysis of DM exhibited a lower proportion of non-polar compounds, which could justify its higher water content. Phenols, more abundant in the OP from the pyrolysis of DM, could come from lignin and protein decomposition. DM is characterized by its lignin and protein content, which could generate phenolic compounds during pyrolysis (especially lignin) (Amen-Chen et al., 2001; Parnaudeau and Dignac, 2007). The greater lignin content of DM could explain the greater proportion of phenols in the OP from the pyrolysis of this residue than in the OP from the pyrolysis of SS. Furthermore, it is noteworthy that no nitrogen-containing aliphatic compounds (such as nitriles) were present in the OP from the pyrolysis of DM. Aliphatic nitriles come from the reaction between fatty acids and ammonia, both produced during pyrolysis. Not enough fatty acids and/or ammonia were 
439 of fatty acids decreased and the proportion of aliphatic nitriles increased in the OP from 440 the pyrolysis of the SS/DM blend in comparison to the predicted average proportions.

441 This could be provoked by the reaction of the fatty acids from the DM pyrolysis with the 442 ammonia from the SS pyrolysis.

446

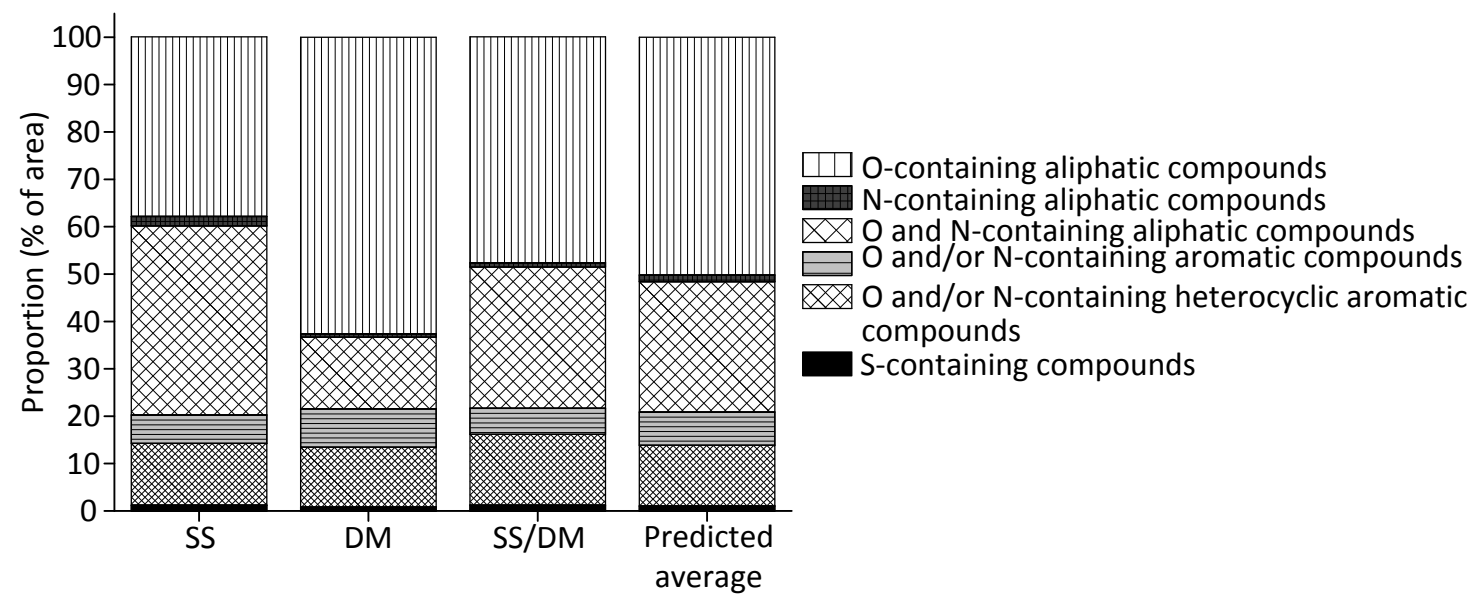

Figure 8. Composition of the AP obtained from the pyrolysis of SS, DM and SS/DM blend.

The area percentages of the different chemical families present in the AP from the pyrolysis of the SS/DM blend were similar to the predicted averages. In this regard, the synergistic effects were less pronounced on the AP than on the OP.

Table 8 shows the chromatographic area percentages of certain organic compounds identified in the aqueous phases. 
Table 8. Chromatographic area percentages of certain organic compounds identified in

456 the AP from the pyrolysis of SS, DM and SS/DM blend.

\begin{tabular}{|l|c|c|c|}
\hline & SS (\%) & DM (\%) & SS/DM (\%) \\
\hline Carboxylic acids & 35.6 & 34.0 & 38.9 \\
Alcohols & 0.5 & 6.2 & 2.1 \\
Ketones & 0.4 & 8.7 & 1.7 \\
Lactones & 0.0 & 4.7 & 1.4 \\
Amides & 19.0 & 4.7 & 13.5 \\
Furans & 0.0 & 4.3 & 2.2 \\
Pyrroles & 9.1 & 4.1 & 5.8 \\
Imidazoles & 7.5 & 1.3 & 7.1 \\
Phenols & 1.7 & 7.5 & 3.5 \\
Pyridines & 7.2 & 5.3 & 7.1 \\
Pyrazines & 0.0 & 2.1 & 3.8 \\
\hline
\end{tabular}

457

Oxygen and nitrogen-containing aliphatic compounds, mainly amides, and oxygencontaining aliphatic compounds, mainly carboxylic acids, were the most abundant families in the AP from the pyrolysis of SS. In the case of DM, carboxylic acids were by far the major organic compounds. Alcohols, ketones and lactones were also significant in the AP from the pyrolysis of DM, which would come from the devolatilization of cellulose or other polysaccharides in the DM (Parnaudeau and Dignac, 2007). Acetic acid was the organic compound found in the greatest proportion in the AP obtained from each individual residue and from the SS/DM blend, being more abundant in the AP from the pyrolysis of DM. This could explain its lower $\mathrm{pH}$. Acetic acid comes from the elimination of acetyl groups present in polysaccharides (Prins et al., 2006), such as cellulose, which are more abundant in DM than in SS. The higher content in polysaccharides of DM could also explain the higher proportion of furans (Parnaudeau and Dignac, 2007) in the AP from the pyrolysis of this residue than that of SS. Again, the greater proportion of phenols in the AP from the pyrolysis of DM than that of SS could be attributed to the higher lignin content of DM. The total proportion of oxygen and/or nitrogen-containing heterocyclic aromatic compounds, mainly pyridines, pyrazines, pyrroles and imidazoles, was similar 
474 for both materials. Pyridines and pyrazines could come from nucleic acids and amino

475 acids with heteroatomic rings (Fullana et al., 2003). Pyridines, which could come from 476 proteins which contain aniline, were more abundant in the AP from the pyrolysis of SS.

477 Pyrazines, which could also derive from the Maillard reaction which involves the 478 formation of N-heterocycles by amino acids interacting with sugars (Schnitzer et al., 479 2007), were only present in the AP from DM. The higher proportion of pyrroles (Tsuge 480 and Matsubara, 1985) and imidazoles in the AP from the pyrolysis of SS was also related 481 to the higher protein content in this residue compared to DM. Acetamide, which could 482 come from the pyrolysis of labile proteins that contain glycine (Parnaudeau and Dignac, 483 2007; Zhang et al., 2013) or from cell wall amino sugars(Eudy et al., 1985), was present 484 in a higher proportion in the AP from the pyrolysis of SS, due to the higher content of 485 proteins in SS. This could contribute to the increase of the $\mathrm{pH}$ of the AP from the SS 486 pyrolysis.

487 3.5. Char characterization

488 The properties of the chars obtained from the different pyrolysis runs are summarized 489 in Table 9. 
Table 9. Properties of the chars obtained from the pyrolysis of SS, DM and SS/DM blend.

491 The values are expressed as mean \pm standard deviation

\begin{tabular}{|l|c|c|c|c|}
\hline \multicolumn{1}{|c|}{ Properties } & SS & DM & SS/DM & Predicted \\
average
\end{tabular}

492

The char obtained from the DM pyrolysis exhibited, in principle, better characteristics 494 for energetic applications than that from the SS pyrolysis: the ash content was lower and 495 the fixed carbon content was higher in the DM char than in the SS char, which led to a higher calorific value in the former. Furthermore, the content of nitrogen and sulfur, which act as contaminants in a fuel, were lower in the DM char. Nevertheless, the ash, nitrogen and sulfur contents of the DM char were still high in comparison with chars from other types of biomass, such as lignocellulosic ones. The char obtained from SS/DM copyrolysis shows no significant interactions between SS and DM. The uses of the char 
501 obtained from the co-pyrolysis could be similar to those proposed for the char from the 502 pyrolysis of each individual residue, such as adsorbent solids and soil amendments. 503 However, the potential application of the char as soil amendment should be corroborated 504 from an agronomic point of view.

505 Figure 9 shows the FTIR results from the char obtained from the pyrolysis of DM, SS 506 and SS/DM blend.

507

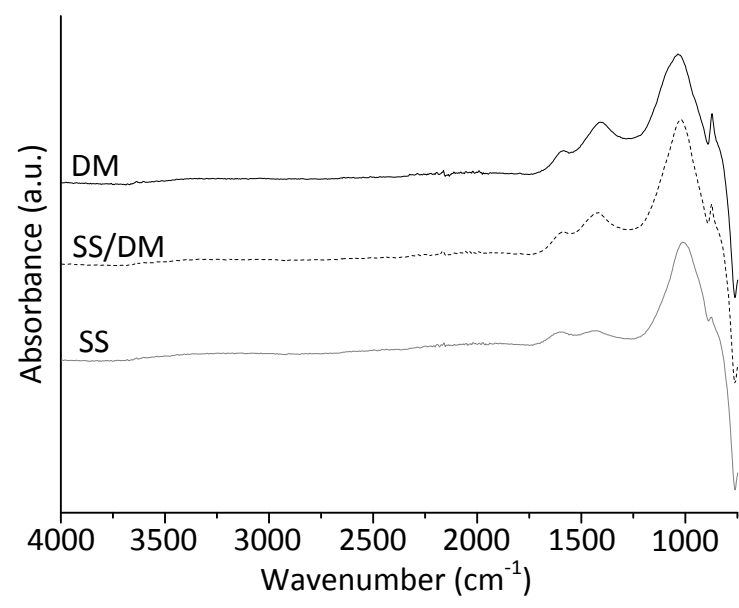

508 Figure 9. FTIR spectra of SS, DM and SS/DM chars.

510 A comparison with the FTIR spectra of the starting materials (shown in Figure 1) shows

511 that pyrolysis causes the reduction or even disappearance of most of the previously 512 identified peak regions. This can be correlated with some of the findings reported in the 513 sections describing the composition of the OP and AP liquid fractions. In particular, the 514 abundance of $\mathrm{N}$-containing compounds, alcohols, phenols and fatty acids in the liquids 515 might account for the absence of the previously identified N-H and O-H stretching (3000$\left.5163700 \mathrm{~cm}^{-1}\right)$ and protein band $\left(1500-1790 \mathrm{~cm}^{-1}\right)$, whereas the reduction of the $\mathrm{C}=\mathrm{O}$ 517 stretching $\left(1409 \mathrm{~cm}^{-1}\right)$ in the case of DM could lead to the formation of oxygenated 518 compounds such as ketones, abundant in the AP from this material. SS/DM chars still 
519 show the presence of calcium carbonate inherited from DM.

520 3.6. Energy analysis

521 The energy yields of the products, based on HHV, indicate the percentage of the initial

522 energy content of the residue contained in each pyrolysis product. Table 10 displays the 523 energy yield results. 
524 Table 10. Energy yields of the products. The values are expressed as mean \pm standard 525 deviation

\begin{tabular}{|l|c|c|c|c|}
\hline & SS (\%) & DM (\%) & SS/DM (\%) & Predicted \\
& & & & average (\%) \\
\hline NCG & $6 \pm 1$ & $6 \pm 2$ & $4 \pm 1$ & $6 \pm 2$ \\
OP & $35 \pm 2$ & $12 \pm 2$ & $24 \pm 2$ & $23 \pm 2$ \\
Char & $33 \pm 1$ & $49 \pm 5$ & $40 \pm 1$ & $41 \pm 5$ \\
Total & $74 \pm 2$ & $67 \pm 5$ & $68 \pm 2$ & $70 \pm 5$ \\
\hline
\end{tabular}

526

527 The total energy yield in the case of the SS pyrolysis was higher than that obtained for the pyrolysis of DM, mainly due to the lower energy recovery of the OP.

The energy balances were calculated for the system shown in Figure 10 to compare the energy requirements for the pyrolysis of each individual residue and for the SS/DM blend.

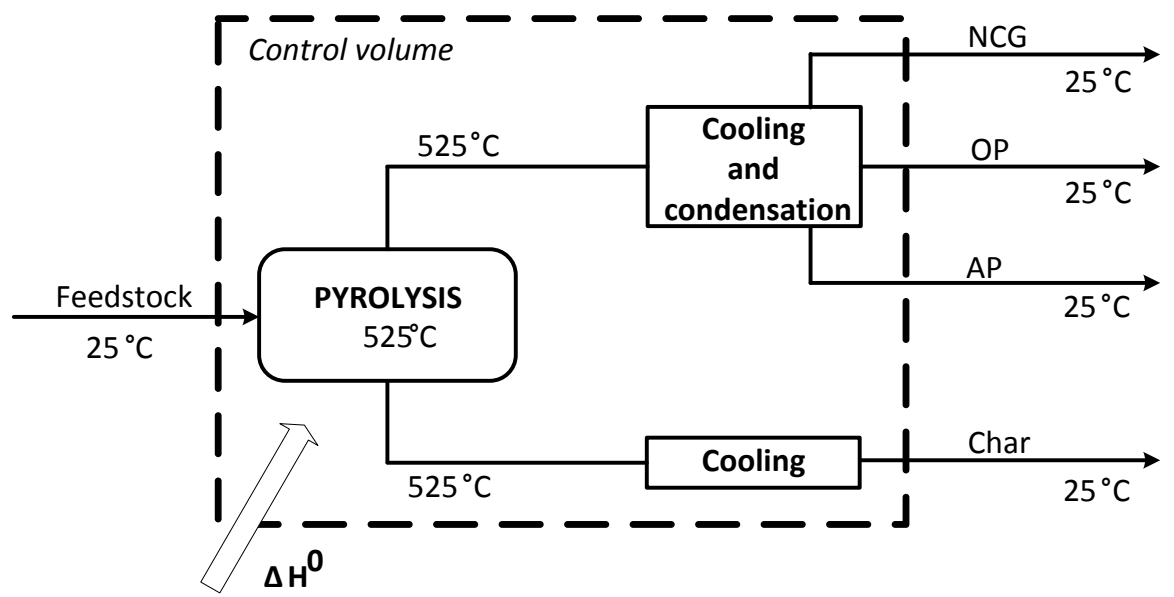

532 Figure 10. Energy balance system for pyrolysis of SS, DM and SS/DM. Reference temperature: $25^{\circ} \mathrm{C}$. Reference pressure: $1.01 \cdot 10^{5} \mathrm{~Pa}$. reference conditions of pressure and temperature $\left(25^{\circ} \mathrm{C}\right.$ and $\left.1.01 \cdot 10^{5} \mathrm{~Pa}\right)$. This means 
537 that the energy released from the cooling of the char and the NCG, and from the cooling 538 and the condensation of the condensable vapors, was completely used. Assuming no heat 539 losses in the system, the input energy ( $\left.\mathrm{H}_{\text {input }}\right)$ included the feedstock chemical energy. The 540 output energy $\left(\mathrm{H}_{\text {output }}\right)$ included the chemical energy of all the products. The chemical 541 energy of the feedstocks, the char and the OP has been calculated from their ultimate 542 analyses and their HHVs. In the case of the AP, the chemical energy has been determined assuming that these phases were a blend of water and acetic acid, which was the most 544 abundant organic component in the aqueous phases.

545 Taking into account the aforementioned simplifications, the $\Delta \mathrm{H}^{0}$, calculated using 546 equation [2], indicates the energy requirement of the process (per kg of feedstock).

$\Delta H^{0}=H_{\text {output }}-H_{\text {input }}=\frac{\sum_{i} \eta_{i} \cdot \Delta H_{f, i}^{0}}{100}-\Delta H_{f, f e e d s t o c k}^{0}$

548 where $\eta_{\mathrm{i}}$ is the yield of each product, $\Delta \mathrm{H}_{\mathrm{f}, \mathrm{i}}^{0}$ the apparent enthalpy of formation of each 549 product and $\Delta \mathrm{H}_{\mathrm{f}, \text { feedstock }}^{0}$ the apparent enthalpy of formation of the feedstock.

550 The $\Delta \mathrm{H}^{0}$ has been calculated for each one of the pyrolysis runs. The results are 551 presented in Table 11.

552 Table 11. $\Delta \mathrm{H}^{0}$ obtained for pyrolysis of SS, DM and SS/DM. The values are expressed 553 as mean \pm standard deviation

\begin{tabular}{|l|c|}
\hline & $\Delta \mathrm{H}^{0}\left(\mathrm{MJ}^{\mathrm{kg}}{ }^{-1}\right)$ \\
\hline $\mathrm{SS}$ & $-0.6 \pm 0.1$ \\
$\mathrm{DM}$ & $-4.2 \pm 0.8$ \\
SS/DM & $-2.1 \pm 0.1$ \\
Predicted average & $-2.4 \pm 0.1$ \\
\hline
\end{tabular}

555 All the values obtained for $\Delta \mathrm{H}^{0}$ were negative which theoretically means that in the 556 absence of heat losses, the energy that could be used from the cooling and condensation 
557 of the products was higher than the energy required for the process. In these terms, the

558 DM pyrolysis and co-pyrolysis of both residues showed much more exothermic behavior 559 than the SS pyrolysis.

560 However, the energy required for the drying of both residues should also be 561 considered. The heat required to reduce the water content of the residues from $65 \%$ 562 (typical minimum humidity value obtained from a mechanical dehydration system) to 7$56310 \%$, which is recommended for the pyrolysis process, was approximately $4 \mathrm{MJ} \cdot \mathrm{kg}^{-1}$ of 564 dried residue (Gil-Lalaguna et al., 2014). Therefore, it is important to efficiently use the of view.

\section{CONCLUSIONS}

The co-pyrolysis of sewage sludge (SS) and digested manure (DM) has been investigated. The char yield from the pyrolysis of DM (dry ash free basis) was higher than that from SS, which is consistent with its higher lignin and lower extractive contents. The pyrolysis of SS produced a gas with higher LHV, but the DM char exhibited better characteristics for energetic applications. The organic compounds and water yields (dry ash free basis) were larger in the pyrolysis of SS, which could be due to its higher extractive and protein contents, respectively.

The liquid obtained from the pyrolysis of each residue showed an aqueous phase and an organic phase. The main compounds in the organic phase from SS were carboxylic 577 acids whereas phenols were the main compounds in the organic phase from DM. The aqueous phases from each residue were rich in carboxylic acids, but the aqueous phase from SS also contained amides in large proportions, which explains its higher $\mathrm{pH}$. 
581 synergistic effects, with the exception of the yields of organic compounds being slightly

582 higher than the predicted average. No remarkable synergistic effects were observed in the

583 liquid phases properties. However, some interactions were detected in the chemical

584 composition of the liquid phases. The proportion of fatty acids decreased and the

585 proportion of aliphatic nitriles increased in the organic phase from the pyrolysis of the

586 SS/DM blend in comparison to the predicted proportions. Finally, no important

587 interactions were found from an energetic point of view. The similar ash contents in SS

588 and DM could explain the small synergistic effect on their co-pyrolysis. Therefore, co-

589 pyrolysis of SS and DM could be a feasible management alternative for these residues in

590 locations where both wastes are generated locally, since the benefits and the drawbacks

591 of the co-pyrolysis are similar to those of the pyrolysis of pure residues.

\section{ACKNOWLEDGEMENTS}

593 The authors would like to acknowledge the use of the Servicio General de Apoyo a la 594 Investigación-SAI and the Instituto de Nanociencia de Aragón (INA), Universidad de 595 Zaragoza. The authors also thank the Centro Tecnológico Agropecuario Cinco Villas for 596 determining protein, lignin, acid detergent fraction and neutral detergent fraction contents 597 in the raw materials. José Antonio Mateo and Olga Marin of I3A are acknowledged for 598 their analytical assistance. The authors would also like to express their gratitude to the 599 Aragon Government and European Social Fund (GPT group) and to MINECO and 600 FEDER (Project CTQ2013-47260-R) for financial support.

\section{REFERENCES}


601

602

603

604

605

606

607

608

609

610

611

612

613

614

615

616

617

618

619

620

621

622

623

624

625

Abrego, J., Arauzo, J., Luis Sanchez, J., Gonzalo, A., Cordero, T., Rodriguez-Mirasol, J., 2009. Structural Changes of Sewage Sludge Char during Fixed-Bed Pyrolysis. Ind. Eng. Chem. Res. 48, 3211-3221.

Abrego, J., Luis Sanchez, J., Arauzo, J., Fonts, I., Gil-Lalaguna, N., Atienza-Martinez, M., 2013. Technical and Energetic Assessment of a Three-Stage Thermochemical Treatment for Sewage Sludge. Energy Fuels 27, 1026-1034.

Agblevor, F.A., Beis, S., Kim, S.S., Tarrant, R., Mante, N.O., 2010. Biocrude oils from the fast pyrolysis of poultry litter and hardwood. Waste Manage. 30, 298-307.

Alvarez, J., Amutio, M., Lopez, G., Bilbao, J., Olazar, M., 2015. Fast co-pyrolysis of sewage sludge and lignocellulosic biomass in a conical spouted bed reactor. Fuel 159, 810-818.

Amen-Chen, C., Pakdel, H., Roy, C., 2001. Production of monomeric phenols by thermochemical conversion of biomass: a review. Bioresour. Technol. 79, 277-299.

Atienza-Martinez, M., Francisco Mastral, J., Abrego, J., Ceamanos, J., Gea, G., 2015. Sewage Sludge Torrefaction in an Auger Reactor. Energy Fuels 29, 160-170.

Aznar, M., Gonzalez, A.E., Manya, J.J., Sanchez, J.L., Murillo, M.B., 2007. Understanding the effect of the transition period during the air gasification of dried sewage sludge in a fluidized bed reactor. International Journal of Chemical Reactor Engineering 5.

Azuara, M., Fonts, I., Barcelona, P., Murillo, M.B., Gea, G., 2013. Study of catalytic posttreatment of the vapours from sewage sludge pyrolysis by means of gamma- $\mathrm{Al}_{2} \mathrm{O}_{3}$. Fuel 107, 113-121.

Brown, T.R., Thilakaratne, R., Brown, R.C., Hu, G., 2013. Techno-economic analysis of biomass to transportation fuels and electricity via fast pyrolysis and hydroprocessing. Fuel 106, 463-469. 
627 Takarada, T., 2011. Preparation and characterization of bio-oils from internally 628 circulating fluidized-bed pyrolyses of municipal, livestock, and wood waste. Bioresour. 629 Technol. 102, 2009-2015.

630 Cuetos, M.J., Gomez, X., Martinez, E.J., Fierro, J., Otero, M., 2013. Feasibility of 631 anaerobic co-digestion of poultry blood with maize residues. Bioresour. Technol. 144, $632 \quad 513-520$.

633 Das, D.D., Schnitzer, M.I., Monreal, C.M., Mayer, P., 2009. Chemical composition of 634 acid-base fractions separated from biooil derived by fast pyrolysis of chicken manure. 635 Bioresour. Technol. 100, 6524-6532.

636 Ding, H.-S., Jiang, H., 2013. Self-heating co-pyrolysis of excessive activated sludge with 637 waste biomass: Energy balance and sludge reduction. Bioresour. Technol. 133, 16-22.

638 Eudy, L.W., Walla, M.D., Hudson, J.R., Morgan, S.L., Fox, A., 1985. Gas 639 chromatography-mass spectrometry studies on the occurrence of acetamide, 640 propionamide, and furfuryl alcohol in pyrolyzates of bacteria, bacterial fractions, and 641 model compounds. J. Anal. Appl. Pyrolysis 7, 231-247.

642 Eurostat, 2014. Sewage sludge production and disposal from urban wastewater treatment 643 plants. http://ec.europa.eu/eurostat/web/products-datasets/-/env_ww_spd (accessed $644 \quad 22.07 .16)$

645 Fonts, I., Gea, G., Azuara, M., Ábrego, J., Arauzo, J., 2012. Sewage sludge pyrolysis for 646 liquid production: A review. Renew. Sust. Energ. Rev. 16, 2781-2805.

647 Fonts, I., Navarro-Puyuelo, A., Ruiz-Gomez, N., Atienza-Martínez, M., Wisniewsky, A., 648 Gea, G., 2016. Assessment of the Production of Value-Added Chemical Compounds from 649 Sewage Sludge Pyrolysis Liquids. Energy Technol. 4, 1-22. 
Fullana, A., Conesa, J.A., Font, R., Martin-Gullon, I., 2003. Pyrolysis of sewage sludge:

651

652

653

654

655

656

657

658

659

660

661

662

663

664

665

666

667

668

669

670

671

672

673

nitrogenated compounds and pretreatment effects. J. Anal. Appl. Pyrolysis 68-9, 561-575.

Gil-Lalaguna, N., Sanchez, J.L., Murillo, M.B., Atienza-Martinez, M., Gea, G., 2014.

Energetic assessment of air-steam gasification of sewage sludge and of the integration of sewage sludge pyrolysis and air-steam gasification of char. Energy 76, 652-662.

Integrated Waste Management Plan of Aragón (Plan GIRA).

Jeong, Y.W., Choi, S.K., Choi, Y.S., Kim, S.J., 2015. Production of biocrude-oil from swine manure by fast pyrolysis and analysis of its characteristics. Renew. Energy 79, 1419.

Kebelmann, K., Hornung, A., Karsten, U., Griffiths, G., 2013. Intermediate pyrolysis and product identification by TGA and Py-GC/MS of green microalgae and their extracted protein and lipid components. Biomass Bioenergy 49, 38-48.

Li, S., Xu, S., Liu, S., Yang, C., Lu, Q., 2004. Fast pyrolysis of biomass in free-fall reactor for hydrogen-rich gas. Fuel Process. Technol. 85, 1201-1211.

Manya, J.J., Sanchez, J.L., Abrego, J., Gonzalo, A., Arauzo, J., 2006. Influence of gas residence time and air ratio on the air gasification of dried sewage sludge in a bubbling fluidised bed. Fuel 85, 2027-2033.

Meng, J., Wang, L., Liu, X., Wu, J., Brookes, P.C., Xu, J., 2013. Physicochemical properties of biochar produced from aerobically composted swine manure and its potential use as an environmental amendment. Bioresour. Technol. 142, 641-646.

Mullen, C.A., Boateng, A.A., 2011. Production and Analysis of Fast Pyrolysis Oils from Proteinaceous Biomass. Bioenerg. Res. 4, 303-311.

Nik-Azar, M., Hajaligol, M.R., Sohrabi, M., Dabir, B., 1997. Mineral matter effects in rapid pyrolysis of beech wood. Fuel Process. Technol. 51, 7-17. 
674 Parnaudeau, V., Dignac, M.-F., 2007. The organic matter composition of various 675 wastewater sludges and their neutral detergent fractions as revealed by pyrolysis-GC/MS. 676 J. Anal. Appl. Pyrolysis 78, 140-152.

677 Prins, M.J., Ptasinski, K.J., Janssen, F., 2006. Torrefaction of wood - Part 2. Analysis of 678 products. J. Anal. Appl. Pyrolysis 77, 35-40.

679 Qu, T., Guo, W., Shen, L., Xiao, J., Zhao, K., 2011. Experimental Study of Biomass 680 Pyrolysis Based on Three Major Components: Hemicellulose, Cellulose, and Lignin. Ind. 681 Eng. Chem. Res. 50, 10424-10433.

682 Ro, K.S., Hunt, P.G., Jackson, M.A., Compton, D.L., Yates, S.R., Cantrell, K., Chang, 683 S., 2014. Co-pyrolysis of swine manure with agricultural plastic waste: Laboratory-scale 684 study. Waste Manage. 34, 1520-1528.

685 Samanya, J., Hornung, A., Apfelbacher, A., Vale, P., 2012. Characteristics of the upper 686 phase of bio-oil obtained from co-pyrolysis of sewage sludge with wood, rapeseed and 687 straw. J. Anal. Appl. Pyrolysis 94, 120-125.

688 Sanchez, M.E., Martinez, O., Gomez, X., Moran, A., 2007. Pyrolysis of mixtures of 689 sewage sludge and manure: A comparison of the results obtained in the laboratory (semi690 pilot) and in a pilot plant. Waste Manage. 27, 1328-1334.

691 Schnitzer, M.I., Monreal, C.M., Jandl, G., Leinweber, P., Fransham, P.B., 2007. The 692 conversion of chicken manure to biooil by fast pyrolysis II. Analysis of chicken manure, 693 biooils, and char by curie-point pyrolysis-gas chromatography/mass spectrometry (Cp 694 Py-GC/MS). J. Environ. Sci. Health Part B-Pestic. Contam. Agric. Wastes 42, 79-95.

695 Schumacher, B.A., 2002. Methods for the determination of total organic carbon (TOC) 696 in soils and sediments, NCEA-C- 1282 EMASC-001. United States Environmental 697 Protection Agency, Las Vegas. 
CHAR. Journal of Applied Polymer Science 29, 1267-1286.

701

Smith, K.M., Fowler, G.D., Pullket, S., Graham, N.J.D., 2009. Sewage sludge-based

702

703

704

705

706

707

708

709

710

711

712

713

714

715

716

717

718

719

720 adsorbents: A review of their production, properties and use in water treatment applications. Water Res. 43, 2569-2594.

Socrates, G., 2004. Infrared and Raman Characteristic Group Frequencies: Tables and Charts, third ed. John Wiley \& Sons, Ltd, Chichester.

Subedi, R., Taupe, N., Pelissetti, S., Petruzzelli, L., Bertora, C., Leahy, J.J., Grignani, C., 2016. Greenhouse gas emissions and soil properties following amendment with manurederived biochars: Influence of pyrolysis temperature and feedstock type. J. Environ. Manage. 166, 73-83.

Troy, S.M., Nolan, T., Leahy, J.J., Lawlor, P.G., Healy, M.G., Kwapinski, W., 2013. Effect of sawdust addition and composting of feedstock on renewable energy and biochar production from pyrolysis of anaerobically digested pig manure. Biomass Bioenergy 49, $1-9$.

Tsuge, S., Matsubara, H., 1985. High-resolution pyrolysis-gas chromatography of proteins and related materials. J. Anal. Appl. Pyrolysis 8, 49-64.

Wright, M.M., Daugaard, D.E., Satrio, J.A., Brown, R.C., 2010. Techno-economic analysis of biomass fast pyrolysis to transportation fuels. Fuel 89, Supplement 1, S2-S10. Zabeti, M., Nguyen, T.S., Lefferts, L., Heeres, H.J., Seshan, K., 2012. In situ catalytic pyrolysis of lignocellulose using alkali-modified amorphous silica alumina. Bioresour. Technol. 118, 374-381. 
721 Zhang, J., Tian, Y., Cui, Y., Zuo, W., Tan, T., 2013. Key intermediates in nitrogen

722 transformation during microwave pyrolysis of sewage sludge: A protein model compound 723 study. Bioresour. Technol. 132, 57-63.

724 Zhang, W., Yuan, C., Xu, J., Yang, X., 2015. Beneficial synergetic effect on gas 725 production during co-pyrolysis of sewage sludge and biomass in a vacuum reactor. 726 Bioresour. Technol. 183, 255-258.

727 Zuo, W., Jin, B., Huang, Y., Sun, Y., 2014. Characterization of top phase oil obtained 728 from co-pyrolysis of sewage sludge and poplar sawdust. Environ. Sci. Pollut. Res. 21, $729 \quad 9717-9726$. 